breeding and its advantages take longer to prove. Moreover, in Sweden, as in Great Britain, superstition is deeply embedded in the minds of the breeders, although it is not, as here, incorporated in official handbooks. The Swedish Animal Breeding Institute with its well-equipped laboratories is situated on an extensive stock farm at Wiad, near Stockholm. Here Prof. Bonnier has set about reducing the difficulties of the problem by applying the latest technical devices. Artificial insemination is used to make rapid progeny tests of young bulls so that the same bulls, and not their progeny, can be bred for stock improvement. Special tests, again with artificial insemination, have been made for the choice of parents in hybridvigour crosses of poultry. New breeding systems have been established for preserving standardized and uniformly cross-bred stocks of poultry by using mixed sperm. These methods are influenced by the hybridvigour technique applied with pre-eminent success by Rasmusson to sugar-beet, and to maize in the United States. Finally, the possibilities of physiological experiment with monozygous twins have been exploited by a national collection of such twins in cattle. This deserves special consideration.

One half per cent of all cattle births are twin heifers. To determine which of these are monozygous a preliminary questionnaire is put to the farmer. Those passing this test are bought and submitted to Kronacher's nose-print and hair-whorl tests. Of the first 215 applications seven pairs fulfilled the conditions of identity. In this way nearly a hundred pairs of monozygous twins have now been collected at Wiad from all over Sweden. With these it has been possible to set up physiological experiments covering the practical problems of nutrition and maintenance. From these experiments the genetical variable has been removed. Already questions have been answered with a certainty which could not otherwise have been attained at fifty times the cost. Further, the answers are of importance far beyond the field of husbandry, especially, of course, in medicine.

The lessons of practical breeding-or production genetics as we may call it-in Sweden have their lessons for Great Britain with its vast responsibilities for farm, forest and fruit crop production at home and overseas. The results depend on a policy consisting of the following coherent elements :

(1) Genetics is taught in the universities;

(2) Posts are available in genetic research for the ablest university students ;

(3) Men are therefore available to teach in the universities who have done research in this subject and thus actually understand how it works.

This is a train of events which a little thought shows is indeed necessary for the healthy development of any science. But this is only one side. The university departments carry on their work in close collaboration with the applied departments of agriculture and medicine and with the research stations. This leads to an integration of subjects and methods. It leads to a realization of the use of statistical, chemical and cytological techniques in genetics, and of genetical techniques in physiology. Finally, the research stations benefit by a direct flow of ideas and of trained personnel from the universities, and them. selves in consequence conduct long-term or 'pure' research of value.

This integration is responsible for what may be described as the engineering method of Swedish plant and animal breeding : a bold combination of scientific basis and long-term planning, with a practical pur- pose and with practical collaboration. The practical collaboration depends again on the Swedish farmer or medical man himself understanding, as a result of education and propaganda, what profit can be gained by using the latest scientific methods. Such a system and such results do not arise by individual effort or accidental whim. They depend upon an instructed national policy.

\section{ADVANCES OF CHEMICAL KINETICS IN THE SOVIET UNION}

\section{BY NIKOLAI SEMENOV}

\author{
Member of the Academy of Sciences of the U.S.S.R.
}

[The school of N. Semenov is well known to physical chemists throughout the world. Its outstanding contribution has been the application of the theory of branching reaction chains to problems of combustion and explosion. - In 1935 Semenov himself published a standard treatise on "Chemical Kinetics and Chain Reactions". His ideas have provided a comparatively easy way through many complex and mysterious phenomena. The following article describes how the theoretical and practical work of his school has developed.-Editors, NATURE.]

T $P$ to the twenties of the present century, "chemical kinetics', or the science of the regularities underlying the course of chemical transformations, was largely in obscurity. But from this time onwards it becomes one of the predominating trends of physico-chemical studies.

As regards homogeneous chemical processes, the concepts of van't Hoff and Arrhenius were to undergo considerable modification. The idea was advanced that the reactions proceed through a number of stages, or intermediate products such as free atoms and radicals or particles excited by electrons. The work of Bodenstein, Haber, Christiansen, Polanyi, Lind, Bäckström and others during 1913-28, especially experiments on the formation of hydrogen chloride and bromide, was the first to suggest the new ideas and the methods of computing the velocities of these reactions. It is in connexion with these studies that the first idea of chain reactions was inaugurated.

It will, however, be noted that no general significance was attached to chain reactions up to 1927. They were considered as confined to very few individual cases.

The situation changed appreciably in 1927, after the publication of the first papers from the Institute of Chemical Physics of the U.S.S.R., and, soon after, of quite independent studies by Hinshelwood and his school in England. It was shown that chain reactions represent a large group of chemical transformations. A theory of chain reactions was developed, new and stimulating ideas were introduced regarding branching of chains and their being cut off on the walls of the vessel : the principal laws of these reactions were deduced and verified experimentally.

From 1928 onwards, these new studies in the domain of chain reactions were discussed at physicochemical congresses and conferences throughout the world, and they have given rise to numerous experimental studies. During 1934-35, Semenov's monograph "Chain Reactions" was published in Russian and in English. This book reviews all the evidence 
bearing on chain reactions and gives an exhaustive and systematic discussion of the theory. In all monographs and books on chemical kinetics, the doctrine of chain reactions occupies a significant place. During 1941-42 an article by Semenov was prepared for press on the general theory of complex reactions, in which a strict mathematical treatment of the theory of chain reactions was presented in a new general form.

The theory of chain reactions postulates that in the course of chemical transformations there appear extremely unstable energy-rich intermediate products (atoms, radicals, unstable peroxides and other labile products). The urgent necessity then arose of determining the nature of these products. The lack of suitable methods still rendered this task almost impossible, and this most important problem could be solved only in one or two cases.

In 1937, the problem was taken up in the laboratory of Prof. Kondratiev (Institute of Chemical Physics). It was shown that, in rarefied flames of hydrogen, free hydroxyl is formed in very great quantities (up to 0.1 per cent of the initial hydrogen) as an intermediate product of oxidation of hydrogen. The amount of hydroxyl is hundreds of thousands times greater than that corresponding to the temperature of the experiment. Kondratiev determined the hydroxyl by a specially devised absorption spectrum method. He also detected CS and SO radicals in the oxidation of carbon disulphide.

Of great interest also is the work of N. Emanuel $(1939-42)$, in which large quantities of SO were shown to appear in the course of carbon disulphide oxidation, and the role of this active intermediate product was established.

A specially detailed study was made of the kinetics of the oxidation of hydrogen and of various hydrocarbons. Naboldin's work (1932-42) showed that the theory of chain reactions accounts for the whole peculiar course of the reactions not only qualitatively but also quantitatively. Concurrently with studies in other countries, the intermediate products of hydrocarbon oxidation were explored in detail, since owing to their relative stability they can be detected with less difficulty. By 'freezing' the reactions at a given stage, Prof. Neuman detected and determined quantitatively by various methods (in particular, polarographic methods) different intermediate products (peroxides, aldehydes, etc.) appearing in the course of oxidation of hydrocarbons.

The phenomenon of cold flames of hydrocarbons, which is very interesting and significant in connexion with detonation in the petrol engine, was subjected to an especially detailed analysis by Prof. Neuman and his collaborators at this Institute (concurrently with the English school of Bone).

Another important branch of chemical kinetics deals with the theory of flame, where chain reactions, as shown in this Institute, mostly play a significant part.

In the twenties of the present century, no satisfactory theory of burning existed-a direct result of the backwardness of chemical kinetics. The work of the Institute of Chemical Physics introduced into the theory the major element, namely, the chemical kinetics of the reactions. This resulted in the establishment of the fundamentals of a theory which accounts for all the principal phenomena associated with burning in gaseous systems. Most of the results obtained are discussed in Semenov's papers (1940-41) under the general title "Theory of Burning", and in articles by Prof. Seldiovich.
In 1927 Semenov formulated the now universally acknowledged theory of thermal explosion. At the same time he defined another type of inflammation, namely, the chain type. It was shown experimentally by Sagulin and others how to differentiate between the two types of explosion.

In 1931 the theory of the 'degenerate' explosion was developed, and also the theory of inhibition of explosion applicable to those cases where slow development of the branching chains (chain 'degenerate' explosion) results in an acceleration of the reaction to the point of thermal ignition. This accounts for the induction period, which sometimes lasts scores of minutes before explosion sets in. These phenomena have been studied in detail in the U.S.S.R. and elsewhere, the results being in full conformity with the theory. Degenerate explosions occur, in particular, in the oxidation of hydrocarbons. The great significance of the induction phenomenon and of the laws studied at the Institute of Chemical Physics on the theory of detonation in the internal combustion engine was soon realized, accounting for the interest aroused by these studies among engineers. All modern theories of detonation in internal combustion engines stand in close relation to the theory of burning, which was largely developed in this Institute.

Prof. Sokolik and his associates not only extended the theory in this direction but have also drawn from it a number of practically important conclusions.

The theory of the slow propagation of the flames with reference to chemical kinetics was first developed by Lewis in the United States (1934). Seldovich and Frank-Kamenetzky of this Institute extended this work by developing a consistent theory of the slow propagation of flame. The validity of the theory was shown experimentally by Baliaev (burning of liquid nitroglycerine), by Semenov and Seldovich (burning of carbon monoxide) and by Kokachashvili and Seldovich (burning of a mixture of hydrogen and bromine).

Just as with thermal self-ignition (calculation of the temperature of self-ignition from kinetic data of the slow process), so in the present case we were able to calculate the absolute value of the rate of flamepropagation in addition to its dependence on temperature, pressure and composition. Seldovich also developed the theory of various practically important phenomena such as limits of inflammation and detonation. $\mathrm{He}$ also completed the theory of the detonation wave, which previously had not been brought into relation with the rate of the actual chemical process.

In this way the phenomena of burning were correlated with chemical kinetics. Burning differs from slow reaction only in one respect-the powerful liberation of heat, and the hydrodynamic phenomena associated with it, influence profoundly the rate of the chemical process. To take these influences into account offers great mathematical difficulties. In developing the theory these have been overcome to a considerable extent, and the formulæ derived from the theory have been verified by experiment.

Concurrently with studies on the burning of gaseous systems, Prof. Khariton's group carried out extensive work on the burning and detonation of explosives. The results obtained are also of fundamental im. portance. Here also many new phenomena have been observed, and the theory has been clarified, but this domain still requires further theoretical work.

It cannot be assumed that we have reached com- 
plete certainty in the theory of burning, or that no unsolved problems will remain in this field of research. Here, as in the theory of chain reactions, a solid basis has been laid, the physical meaning of the processes has been clarified, and the method of approach established. Nevertheless, each individual reaction requires a special study, its specific character being different.

In this way we have worked step by step during the last twenty-five years in developing chemical kineties in close contact with the English and American men of science who have frequently attended our conferences or sent us their papers.

Now our work has been interrupted. Many young workers of this Institute voluntarily joined the army during the first days of the War ; one of my closest associates and followers, P. Sadovnikov, whose name is known among scientific circles of Great Britain, has been killed. But the majority of our collaborators are still in the laboratories of the Institute, where work has been greatly intensified.

\section{HYDRO-ELECTRIC DEVELOPMENT IN SCOTLAND}

$\mathrm{O}^{\mathrm{N}}$ October 27, 1941, the Lord Advocate for Scotland, then the Right Hon. Lord Cooper, was appointed chairman of a committee of five to inquire into a report on hydro-electric development in Scotland. The report now issued* is dated August 24, 1942-so the Committee wasted no time. The Committee recognizes that hydro-electric planning is a matter for many years ahead--though it may not be out of place to remark that the national grid in Great Britain is an established success for war as well as peace conditions.

In the historical survey, the record of the last twenty years, with its six successive abortive promotions, comes boldly and badly into the picture. All major issues of policy, both national and local, have tended to become completely submerged in the conflict of contending national interests. But even governments do not escape if their policy is that they will neither develop the resources themselves nor allow anyone else to do so.

Excluding all burghal areas, the overall density of population on the mainland of the Northern Area is less than 20 per square mile. Northern Scotland is the only part of Great Britain not covered by the Grid scheme. The Committee finds that for such an area the policy embodied in the 1926 Act (which led to the formation of the Central Electricity Board) is essentially inappropriate and inapplicable. The progress of the Grampian Company, the control of which was obtained by the Scottish Power Company, in 1927, is traced. By supplying 106 million units per annum to the Central Electricity Board, the Grampian Company has an assured market to enable it to embark on a general supply in an extensive and sparsely populated territory. In 1940, the units sold, other than to the Central Electricity Board, totalled 63 million at an average of $1.55 d$. per unit. Here, then, is indicated a practical way for development. The Committee considers these results to justify the decision of the Electricity Commissioners and Central

- Scottish Office. Report of the Committee on Hydro-Electric Development in Scotland. (Cmd. 6406.) Pp. 38. (London and EdinDevelopment in Scotland. (Cmd. 6406.) Pp. 38.
burgh : H.M. Stationery office, 1942.) $9 d$. net.
Electricity Board in 1931 to leave the development of this area to the Grampian Company.

Commenting on the criticisms against the Grampian Company, the report shows a sympathetic appreciation. Even so, doubts may still exist. On one occasion, when the present writer was visiting the Loch Rannoch and Tummelbridge Works, it struck him as strange to see two joiners making a coffin by candlelight in a house in the village of Kinloch Rannoch.

In the existing state, it is stressed that it will be essential at the earliest possible date to provide a substantial new source of power in the extreme north of the Grampian territory, to meet normal expansion. To construct a large steam station in a district so remote from coal and so rich in water-power would involve a major error of misplanning. It is not agreed that the cancellation of the bulk supply to the Central Electricity Board would solve the problem, both because of the effect of the loss of the contract, and the fact that Loch Rannoch and Tummelbridge Works have been designed for a 50 per cent load factor and not for supplying a general demand.

In the study of comparative costs of steam and hydro-electric generation, attention is directed to the rising price of coal in recent years, and in the fall in the basic rate of interest-the main components in the cost of electricity generated from steam and water respectively. On the financial side, the Committee considers its recommendations preferable to the provision of an equivalent capacity of new steam plant. Any likely improvement in water or steampower technique is unlikely to influence the position. Provisional estimates disclose some seventy favourable schemes in the Northern Area capable of yielding not less than 4,000 million units per annum, or $450,000 \mathrm{~kW}$. continuous.

Of the opposing theories for revitalizing the Highlands, the Committee regards the introduction of modern industries in which an abundant supply of cheap electricity is indispensable as the only means of securing a prosperous population in the area. These industries are electro-chemical and electrometallurgical: calcium carbide and cyanamide; reduction or refining processes for aluminium, copper, zinc, vanadium and cadmium; the ferro-alloys. The defeat of the Caledonian Power Bill is regarded as a tragic mistake, not only for Scotland but also for Great Britain. Assuming that these industries on a substantial scale are essential to Great Britain, northern Scotland offers the only solution. By suitable planning, natural beauty can be preserved. The Committee challenges the critics to offer any other scheme to arrest the growing decay in the Highlands.

From independent computations, it is found that the ultimate local demand for general supply represents about 8 per cent of the ultimate power capable of development; consequently the position for the local population would be adequately safeguarded. In the long-term plan of development, the national grid forms the indispensable background as a market for surplus power.

The Committee's recommendations include the creation of a non-profit-earning, public-service corporation to work in close partnership with the Central Electricity Board. This new corporation would be responsible for the further development of electricity generation, transmission and distribution in the Northern Area. The corporation should attract to the Highlands a share of the industries demanding abundant and cheap power, develop such further 